\title{
PERAN KEPALA SEKOLAH DALAM MENINGKATKAN PROFESIONALISME GURU DI SMP MUHAMMADIYAH 36 JAKARTA SELATAN
}

\author{
Rosalina Dewi Heryani ${ }^{1(*)}$, Irna Kumala ${ }^{2}$ \\ Universitas Indraprasta PGRI, Jakarta ${ }^{12}$ \\ rosalina.dewi7@gmail.com ${ }^{1}$, irnakumala@yahoo.com ${ }^{2}$
}

\begin{abstract}
Received: 21 Februari 2020

Revised: 09 Maret 2020

Penelitian yang dilakukan bertujuan untuk mengetahui Peran Kepala

Accepted: 15 Maret 2020

Sekolah dalam Meningkatkan Profesionalisme Guru. Metode penelitian yang digunakan yaitu kuantitatif deskriptif. Jumlah sampel yang digunakan sebanyak 17 guru. Berdasarkan hasil penelitian peran kepala sekolah yang terdiri dari enam dimensi diperoleh simpulan sebagai berikut : Peran kepala sekolah dengan nilai tertinggi 50,8 yaitu dimensi educator. Dikuti dengan dimensi leadership nilainya 49,17, dimensi manajer nilainya 46,67, dimensi inovator nilainya 46 , dimensi motivator nilainya 45,5, dan dimensi supervisor nilainya 45. Simpulannya Peran Kepala Sekolah dalam Meningkatkan Profesionalisme Guru di SMP Muhammadiyah 36 Jakarta Selatan masuk ke dalam kategori Cukup Baik.

Keywords: Peran Kepala Sekolah, Upaya Peningkatan Profesionalisme Guru, Profesionalisme Guru
\end{abstract}

(*) Corresponding Author: $\quad$ Rosalina Dewi Heryani, rosalina.dewi7@ gmail.com, 08568688130

How to Cite: Heryani, R. D. \& Kumala, I. (2020). Peran Kepala Sekolah Dalam Meningkatkan Profesionalisme Guru Di Smp Muhammadiyah 36 Jakarta Selatan. Research and Development Journal of Education, 6(2), 24-30.

\section{INTRODUCTION}

Kepala sekolah memiliki peran penting dalam penyelenggaraan kegiatan belajar mengajar di sekolah. Kepala sekolah merupakan seorang guru yang diberikan kepercayaan untuk mengemban jabatan struktural disekolah yang tugas utamanya adalah melakukan interaksi antara guru, orangtua peserta didik, peserta didik, dan semua warga sekolah. Di dalam lingkungan sekolah terdiri dari beragam manusia yang memiliki latar belakang yang berbeda. Disinilah kepala sekolah harus mampu menjalankan perannya sebagai penengah jika terjadi permasalahan di lingkungan sekolah tempatnya bertugas.

Kepala sekolah merupakan kunci utama perkembangan, peningkatan, dan keberhasilan suatu sekolah. Peningkatan kinerja guru dalam proses pendidikan dapat tercapai apabila kepala sekolah hadir dan mampu meningkatkan profesionalisme guru. Mutu sekolah ditentukan oleh banyak hal, bukan saja oleh jumlah guru dan kompetensinya, namun banyak ditentukan oleh peran kepala sekolah dalam menjalankan tugas dan tanggung jawabnya. Untuk meningkatkan mutu pendidikan, salah satu cara yang dapat ditempuh adalah dengan memberdayakan dan memaksimalkan semua potensi yang ada semaksimal mungkin. Salah satu bentuk nyata dengan melakukan pemberdayaan guru dalam mengajar yaitu dengan mengoptimalkan kompetensi dasar guru. Pada kenyataannya dilapangan, masih banyak ditemukan kelemahan-kelemahan yang ada terkait proses pendidikan di sekolah. Salah satu kelemahan yang ditemukan adalah manajemen yang sangat sederhana baik itu mengenai Sumber Daya Manusia, 
kurikulum, dan komponen pendidikan lainnya sehingga pendidikan tidak direncanakan dengan baik.

Guru mempunyai peran yang sangat strategis dalam pembentukan pengetahuan, keterampilan, dan karakter peserta didik. Guru harus dapat melaksanakan tugasnya secara profesional sehingga mampu menghasilkan lulusan berakhlak, bermutu, dan berdaya saing tinggi dalam dunia kerja. Menjadi guru profesional tidaklah mudah. Salah satu langkah strategis yang dapat ditempuh untuk memberdayakan guru yaitu dengan menggerakkan para guru agar kinerjanya meningkat karena kinerja guru merupakan cerminan kualitas pendidikan di sekolah. Guru akan bekerja secara optimal apabila didukung oleh beberapa faktor, diantaranya kepemimpinan kepala sekolah.

Profesionalisme guru merupakan sebuah kondisi yang memiliki arah dan tujuan dalam peningkatan kualitas suatu keahlian dalam bidang pendidikan dan pengajaran. Guru yang memiliki kompetensi yang baik dalam hal proses pembelajaran terbentuk dari adanya profesionalisme yang tinggi. Guru dituntut harus profesional, mampu mengajar dengan baik, mampu merancang, memilih bahan ajar, dan strategi pembelajaran yang dapat menyesuaikan dengan keadaan peserta didik, serta mampu mengelola proses pembelajaran dan melakukan evaluasi untuk mengukur penguasaan hasil belajar. Sebagai pendidik, seorang guru bertugas membimbing, mengajar, membina, mengarahkan peserta didik kearah yang lebih baik agar lebih aktif dalam bertanya, kreatif dalam berpikir, dan mandiri dalam bertindak dan berkarya. Dalam International Journal of Education dijelaskan bahwa "professionalism requires three essential characteristic : high levels of proffesional knowlede, skills and dispositions" (Minsun, 2012).

Guru yang profesional harus menguasai empat kompetensi dasar, antara lain kompetensi pedagogik, profesional, kepribadian, dan sosial. Empat kompetensi dasar ini saling mendukung satu sama lain dan tidak terpisahkan. Kompetensi dapat diartikan sebagai kumpulan kemampuan, kecakapan, pengetahuan, sifat, sikap, pemahaman, apresiasi, dan harapan yang menjadi karakteristik seseorang untuk menjalankan tugasnya dalam mencapai standar kualitas pekerjaannya. Selain itu diperkuat oleh jurnal pendidikan bahwa "teachers see the pedagogical and moral tasks as an important part of their job and this is apparent not only quantitative data but also from the qualitative research finding. Teacher oftne try to place themselve in the position of the student to understand the personalities of the studen" (Cess, 2000).

Penelitian serupa telah banyak dilakukan. Namun ada beberapa perbedaan antara penelitian ini dengan penelitian sebelumnya, antara lain jenis penelitian dan dimensinya (Inayati, 2014), teknik pengumpulan datanya (Murtafiah, 2008), dan jenjang pendidikan (Mu'min, 2011).

\section{LITERATURE REVIEW}

\section{Peran Kepemimpinan Kepala Sekolah}

Menurut Kamus Besar Bahasa Indonesia, peran adalah kumpulan perilaku yang harus dimiliki oleh seseorang yang berkedudukan di masyarakat. Sedangkan menurut Rivai dan Murni (2009:745), peran merupakan perilaku yang diatur dan diharapkan dari seseorang dalam posisi tertentu. Menurut Daryanto (2010:80), kepala sekolah merupakan warga sekolah yang memiliki tanggung jawab terhadap seluruh kegiatan yang dilakukan di sekolah, mempunyai wewenang untuk menyelenggarakan seluruh kegiatan pendidikan di lingkungan sekolah yang dipimpinnya.

Mulyasa (2004:100) menyatakan bahwa untuk meningkatkan kualitas tenaga kependidikan terutama guru, kepala sekolah harus memiliki peran antara lain : 
1. Kepala sekolah sebagai educator (pendidik), melakukan pembinaan mental, moral dan fisik bagi tenaga kependidikan.

2. Kepala sekolah sebagai manajer, merupakan suatu proses dalam merencanakan, mengorganisasikan, melaksanakan, memimpin, dan mengendalikan usaha seluruh warga sekolah, serta mampu mendayagunakan seluruh sumber daya untuk mencapai tujuan yang telah ditentukan.

3. Kepala sekolah sebagai supervisor, memiliki kemampuan untuk melakukan pengawasan dan pengendalian guna peningkatan kinerja bawahannya yaitu tenaga kependidikan.

4. Kepala sekolah sebagai leader, memiliki kemampuan memberikan petunjuk, pengawasan, menumbuhkan motivasi tenaga kependidikan, melakukan komunikasi dua arah, dan mendelegasikan tugas sesuai tanggung jawabnya.

5. Kepala sekolah sebagai inovator, memiliki strategi yang tepat guna menjalin hubungan yang harmonis, mencari ide baru, mengintegrasikan kebijakan dan kegiatan, memberikan keteladanan kepada seluruh warga sekolah, dan mengembangkan model pembelajaran yang kreatif, aktif, serta inovatif.

6. Kepala sekolah sebagai motivator, memiliki kemampuan merancang strategi yang tepat untuk memotivasi tenaga kependidikan dalam menjalankan tugas dan fungsinya. Motivasi ini ditumbuhkan melalui pengaturan lingkungan fisik, suasana kerja, disiplin, pemberian penghargaan berkala, dan penyediaan berbagai sumber belajar.

Keberhasilan seorang kepala sekolah mengelola manajemen sekolah sangat dipengaruhi oleh beberapa hal, diantaranya kondisi kepala sekolah itu sendiri, faktor dukungan bawahan, dan faktor lingkungan. Menurut Hidayat dan Asroi (2013:67-68), hal-hal berikut ini yang harus dimiliki oleh kepala sekolah untuk dapat menjalankan peran dan tugasnya, antara lain :

1. Kepribadian yang kuat, seperti bersemangat, berani, percaya diri, murah hati, dan memiliki kepekaan sosial.

2. Memahami tujuan pendidikan dengan baik, dengan bekal pemahaman terhadap tujuan sekolah maka kepala sekolah diharapkan dapat menjelaskan kepada seluruh stakeholders serta menggunakan strategi yang tepat untuk mencapai tujuan tersebut.

3. Memiliki pengetahuan yang luas, yaitu penguasaan terhadap ilmu tentang kepemimpinan dan pengetahuan lainnya yang terkait dengan bidang tugasnya sebagai seorang kepala sekolah.

4. Memiliki keterampilan profesional, yaitu :

a. Memiliki keterampilan teknis sebagai kepala sekolah dalam mengelola, mensupervisi, dan memimpin berbagai kegiatan.

b. Keterampilan hubungan manusia seperti mampu mendorong, memotivasi, dan mengembangkan bawahan.

c. Keterampilan konseptual, yakni kemampuan mengembangkan sekolah, memprediksi berbagai persoalan kedepan dan mampu mencari solusinya.

\section{Profesionalisme Guru}

Profesionalisme guru merupakan faktor yang sangat menentukan keberhasilan sebuah sekolah. Jabatan guru sebagai profesi menuntut adanya keahlian dan keterampilan khusus dibidang pendidikan dan pengajaran. Jabatan guru bukan merupakan sekedar pekerjaan yang hanya pelampiasan mencari nafkah dengan modal pengetahuan dan keahlian yang pas-pasan. Guru profesional adalah seseorang yang memiliki kompetensi mendalam dan langsung menyentuh masalah inti pendidikan, yaitu pengetahuan dan keterampilan. Guru juga perlu melakukan perbaikan kemampuan ilmu yang diajarkan dan perbaikan metode pengajaran guna mencapai proses pembelajaran yang optimal. 
Menurut Sudarwan (dalam Hidayat dan Asroi, 2013:76), Guru profesional memiliki ciri-ciri sebagai berikut :

1. Dapat berkomunikasi secara luwes. Seseorang yang profesional cenderung memiliki tingkat kematangan emosi yang stabil. Kemampuan berinteraksi dan berkomunikasi sangat erat kaitannya dengan tingkat kematangan emosi guru itu sendiri.

2. Mengenal serta melaksanakan administrasi, baik administrasi kegiatan sekolah maupun administrasi guru adalah suatu hal yang mutlak dilakukan oleh seorang guru, karena guru selain sebagai educator juga sebagai administrator.

Menguasai landasan pendidikan. Guru yang profesional menguasai dan memahami landasan kependidikan sebagai acuan kinerjanya. Indikator penguasaan landasan pendidikan antara lain mengenal tujuan pendidikan nasional, mengenal fungsi sekolah dalam masyarakat, dan mengenal prinsip psikologi.

\section{METHODS}

1. Jenis Penelitian

Jenis penelitian ini adalah kuantitatif deskriptif, dimana dalam penelitian ini peneliti hanya mengolah, menyajikan data, dan mendeskripsikan hasil penelitian tanpa mencari hubungan antara variabel.

2. Populasi dan Sampel

Penelitian ini dilakukan di SMP Muhammadiyah 36 Jakarta pada bulan Oktober Desember 2019. Populasi penelitian adalah seluruh guru yang berjumlah 18 orang. Jumlah sampel sebanyak 17 orang. Teknik sampling yang digunakan adalah insidental sampling.

3. Teknik Pengumpulan Data

a. Observasi

Observasi yang dilakukan peneliti adalah dengan pengamatan langsung terhadap objek penelitian dengan menggunakan lembar observasi dengan cara memberi tanda checklist $(\sqrt{ })$. Dalam hal ini peneliti melakukannya dengan cara mengamati lingkungan sekolah, bangunan, sarana prasarana, dan interaksi antara peserta didik, guru dengan kepala sekolah.

b. Angket Angket diberikan kepada responden terdiri dari 30 pernyataan yang dibagi menjadi 6 dimensi.

c. Dokumentasi

Dokumentasi dipergunakan untuk memperkuat proses penelitian. Terkait dengan objek penelitian, maka dokumen yang diperlukan antara lain buku-buku, jurnal, dan lainnya.

4. Teknik Pengolahan dan Analisis Data

Teknik pengolahan dan analisis data yang digunakan oleh peneliti untuk menjawab penelitian sebagai berikut :

a. Teknik Pengolahan Data

Langkah-langkah yang digunakan oleh peneliti antara lain :

1) Editing, pada tahap ini peneliti melakukan pengecekan kelengkapan serta kebenaran dalam pengisian angket yang dilakukan responden agar data yang diperoleh akurat.

2) Skoring, peneliti memberikan skor pada setiap butir pernyataan yang tertera di angket. Butir jawaban tersebut ada empat, antara lain selalu (4), sering (3), kadangkadang (2), dan tidak pernah (1). 
3) Tabulating, setelah diketahui skor dari tiap indikator, selanjutnya seluruh data ditabulasikan kedalam tabel dan kemudian diketahui hasil perhitungannya.

b. Teknik Analisis Data

Peneliti menggunakan teknik analisis data deskriptif

\section{RESULTS \& DISCUSSION}

\section{Results}

Berikut ini adalah data hasil perhitungan rata-rata skor Peran Kepala Sekolah dalam Meningkatkan Profesionalisme Guru di SMP Muhammadiyah 36 Jakarta Selatan.

Tabel 1.

Rata-Rata Hitung Skor Peran Kepala Sekolah Dalam Meningkatkan Profesionalisme Guru

\begin{tabular}{ccccccc}
\hline Variabel & \multicolumn{5}{c}{ Peran Kepala Sekolah dalam Meningkatkan Profesionalisme Guru } \\
\hline Dimensi & Leadership & Supervisor & Motivator & Inovator & Manajer & Educator \\
Jumlah Soal & 6 & 6 & 4 & 3 & 6 & 5 \\
Skor & 295 & 270 & 182 & 138 & 280 & 254 \\
Rata-rata & 49,17 & 45 & 45,5 & 46 & 46,67 & 50,8 \\
\hline
\end{tabular}

Sumber: Diolah Peneliti, 2019

Berdasarkan data diatas, kemudian dilakukan perhitungan sebagai berikut :

$$
\frac{49,17+45+45,5+46+46,67+50,8}{6}=47,19
$$

Kemudian nilai tersebut di interpretasikan ke dalam tabel berikut ini :

Tabel 2.

Tabulasi Skor

\begin{tabular}{ccc}
\hline No. & Nilai Skor & Kategori \\
\hline 1 & $95-120$ & Sangat Baik \\
2 & $70-94$ & Baik \\
3 & $45-69$ & Cukup Baik \\
4 & $20-44$ & Kurang Baik \\
\hline
\end{tabular}

\section{Discussion}

Berdasarkan hasil perhitungan diatas, maka dapat dijelaskan sebagai berikut:

a. Dimensi leadership, Kepala Sekolah dalam menentukan dan menjalankan kebijakan pendidikan mendapatkan skor rata-rata sebesar 49,17 dengan kategori cukup baik.

b. Dimensi supervisor, Kepala Sekolah dalam mengawasi dan mengarahkan guru mendapatkan skor rata-rata sebesar 45 dengan kategori cukup baik.

c. Dimensi motivator, Kepala Sekolah dalam meningkatkan kinerja guru mendapatkan skor rata-rata sebesar 45,5 dengan kategori cukup baik.

d. Dimensi inovator, Kepala Sekolah dalam melaksanakan strategi kepemimpinan mendapatkan skor rata-rata sebesar 46 dengan kategori cukup baik.

e. Dimensi manajer, Kepala Sekolah dalam mengendalikan kepemimpinan mendapatkan skor rata-rata sebesar 46,67 dengan kategori cukup baik.

f. Dimensi educator, Kepala Sekolah dalam meningkatkan profesionalisme guru mendapatkan skor rata-rata sebesar 50,8 dengan kategori cukup baik. 
Dengan demikian secara keseluruhan dari keenam dimensi yang merupakan indikator peran kepala sekolah dalam meningkatkan profesionalisme guru di SMP Muhammadiyah 36 Tebet dikatakan cukup baik. Berdasarkan hasil perhitungan angket, peneliti menemukan beberapa kekuatan dan kelemahan dari kepala sekolah dalam menjalankan perannya. Untuk kekuatan kepala sekolah antara lain :

a. Kepala sekolah memiliki sikap yang jujur.

b. Kepala sekolah meningkatkan sarana dan prasarana yang memadai.

c. Kepala sekolah memberikan kesempatan kepada guru yang ingin melanjutkan studinya.

Sedangkan untuk kelemahan kepala sekolah antara lain:

a. Kepala sekolah belum maksimal dalam melakukan komunikasi secara aktif dan efektif.

b. Kepala sekolah belum maksimal dalam membantu menyelesaikan masalah yang sedang dihadapi guru.

c. Kepala sekolah belum maksimal dalam membangun kedekatan yang positif dengan guru.

d. Kepala sekolah belum maksimal dalam memiliki ide yang cemerlang terkait kemajuan sekolah.

\section{CONCLUSION}

Berdasarkan hasil penelitian dan pembahasan, maka Peran Kepala Sekolah dalam Meningkatkan Profesionalisme Guru di SMP Muhammadiyah 36 Jakarta Selatan Cukup Baik. Hal ini berdasarkan perhitungan rata-rata skor yang terdiri dari enam dimensi, yaitu leadership, supervisor, motivator, inovator, manajer, dan educator.

\section{REFERENCES}

Cess A, Klaassen. (2010). An International Journal of Research and Studies Teaching and Teacher Education. Vol. 18.

Daryanto, M. (2010). Administrasi Pendidikan.Jakarta:Rineka Cipta.

Hartono. (2004). Statistik Untuk Penelitian.Yogyakarta:PT. Pusaka Pelajar.

Hidayat, Syarif dan Asroi. (2013). Manajemen Pendidikan. Tangerang: PT. Pustaka Mandiri.

Husaini, Usman. (2009). Metodologi Penelitian Sosial.Jakarta:PT. Bumi Aksara.

Inayati, Nurul Latifatul. (2014). Peran Kepala Sekolah dalam Meningkatkan Profesionalisme Guru di Sekolah Menengah Pertama (SMP) Muhammadiyah 3 Kaliwungu dan SMP Muhammadiyah 6 Kendal.

Minsun, Shin. (2012). Jounal International of Education Whole Teachers Crisis: Examining preservice Student Teachers Perceptions of Professionalism.Vol. 4, No. 4.

Mulyasa, E. (2004). Menjadi Kepala Sekolah Profesional dalam Konteks Menyukseskan MBS dan KBK. Bandung: PT. Remaja Rosda Karya.

Mu'min, Abdul. (2011). Peranan Kepala Sekolah dalam Meningkatkan Profesionalisme Guru di SDI Al-Ihsan Bambu Apus Pamulang.

Murtafiah, Tsani. (2008). Peranan Kepala Sekolah dalam Meningkatkan Profesionalisme Guru di MIN Panjang Ambarawa. 
Heryani \& Kumala / Reseacrh and Development Journal of Education, 6(2), 24-30

Rivai, Veithzal dan Murni, Sylviana. (2009). Education Management: Analisis Teori dan Praktik. Jakarta: PT. Raja Grafindo. 